\title{
Fabrication and Characteristics of Organic Thin-film Solar Cells with Active Layer of Interpenetrated Hetero-junction Structure
}

\author{
Im-Jun No ${ }^{1}$, Paik-Kyun Shin ${ }^{1}$, Santhakumar Kannappan ${ }^{2}$, Palanisamy Kumar ${ }^{2} \&$ Shizuyasu Ochiai $^{2}$ \\ ${ }^{1}$ Department of Electrical Engineering, Inha University, \#253 Yonghyun-dong, Nam-gu, Incheon, Korea \\ ${ }^{2}$ Department of Electrical Engineering, Aichi Institute of Technology, Toyota, Aichi, Japan \\ Correspondence: Prof. Shizuyasu Ochiai, Department of Electrical Engineering, Aichi Institute of Technology, \\ Toyota, Aichi 470-0392, Japan. Tel: 81-56-548-8121. E-mail: ochiai@aitech.ac.jp
}

$\begin{array}{lc}\text { Received: September 5, } 2012 & \text { Accepted: September 20, } 2012 \text { Online Published: October 17, } 2012 \\ \text { doi:10.5539/apr.v4n4p83 } & \text { URL: http://dx.doi.org/10.5539/apr.v4n4p83 }\end{array}$

\begin{abstract}
Interpenetrated hetero-junction structures based on poly[[4,8-bis[(2-ethylhexyl)oxy]benzo[1,2-b:4,5 -b']dithiophene-2,6-diyl][3-fluoro-2-[(2-ethylhexyl)carbonyl]thieno[3,4-b]thiophenediyl] (PTB7)/[6,6]-Phenyl $\mathrm{C} 71$ butyric acid methyl ester( $\left.\mathrm{PC}_{71} \mathrm{BM}\right)$ were prepared for organic solar cell device fabrication by using wet process combination of spin-coating (PTB7) and spray-coating $\left(\mathrm{PC}_{71} \mathrm{BM}\right)$. Precursor solutions for the wet process of active layers were prepared with 1,8-Diiodooctane(DIO) as additive solvent and four different hetero-junction structures were prepared. Light absorbance and surface morphology for each single layer and hetero-junction structures were investigated by UV-Vis spectrometer and AFM, respectively. J-V characteristics of the resulting organic solar cell devices were measured to evaluate their performance. The interpenetrated hetero-junction structure of $\mathrm{PTB} 7 / \mathrm{PC}_{71} \mathrm{BM}$ prepared with $\mathrm{DIO}$ additive attributed to drastic increase of power conversion efficiency $(\eta=3.54 \%)$ from that $(\eta=1.24 \%)$ of without DIO additive.
\end{abstract}

Keywords: organic photovoltaic device, interpenetrated hetero-junction, PTB7, PC71BM

\section{Introduction}

Organic solar cell (OSC) devices based on organic active layer has been studied focusing on several advantages over inorganic solar cells (Yang, Chen, Yu, Wang, \& Yan, 2012; Nam, Huh, \& Jo, 2010; Ohkita \& Ito, 2011). In general, OSC devices have been fabricated by using wet process technologies for preparation of organic thin films such as spin-coating and drop-casting methods. Spin-coating and drop-casting methods are advantageous due to ease of process and possibility of obtaining high-quality thin films, so that they could be adaptable to mass production processes like roll-to-roll process. On the other hand, successive deposition for multiple organic layerscould hardly be done by spin-coating and drop-casting technologies, when the precursor solutions for each layer are prepared by using the same solvent, and hence, solvents should be carefully selected to prevent from damaging underlying organic layers. However, almost all the representative organic semiconductor materials might be easily attacked by typical solvents, so that stacking process essential for organic thin film device fabrication could not be done by using spin-coating and drop-casting methods and adaptability of organic materials for OSC devices would be considerably limited. Meanwhile, spray-coating methods spraying fine liquid organic vapor would be favorable to minimize physical damage to underlying layers, which is inevitable in spin-coating process due to considerable centrifugal force spread out on surface of underlying layers on substrate (Park et al., 2011).

To date, bulk hetero-junction (BHJ) structure is representative for organic thin film solar cell devices (Park et al., 2009; Liang et al., 2010). BHJ structure has been suggested to overcome ineffective charge carrier separation in interface of electron accepter-electron donor hetero junction (Dennler, Scharber, \& Brabec, 2009; Deibel \& Dyakonov, 2010; Deibel, Dyakonov, \& Brabec, 2010). However, charge carrier transfer path is complicated due to blended structure of electron donor and electron acceptor materials, and control of phase separation for electron donor and electron accepter materials are quite difficult. To solve this problem, an interpenetrated structure of electron donor and electron accepter has been suggested as an alternative (Liang et al., 2010). In this report, advantages of spin-coating and spray-coating process were tried to be combined to fabricate an organic thin film solar cell device with an interpenetrated structure of organic active layers, where spray-coated electron accepter layer was prepared on spin-coated electron donor layer. Owing to high throughput, large area coat and ability to 
deposit broad range of fluids with different rheologies, spray coating process is considered to be a valid alternative for spin coating. Performance of the organic thin film solar cell devices was investigated to evaluate feasibility of the suggested interpenetrated hetero-junction structure of electron donor and electron accepter.

\section{Experimental}

\subsection{Preparation of Precursor Solutions for Organic Polymer Active Layers}

As for electron donor, organic polymer semiconductor layer of poly[[4,8-bis[(2-ethylhexyl)oxy]benzo[1,2b:4,5-b']dithiophene-2,6-diyl][3-fluoro-2-[(2-ethylhexyl)carbonyl] thieno[3,4-b] thiophenediyl]] [PTB7] (1-material) was deposited. As for an electron acceptor, organic polymer semiconductor layer of [6,6]-Phenyl $\mathrm{C} 71$ butyric acid methyl ester $\left[\mathrm{PC}_{71} \mathrm{BM}\right]$ (American Dye Source, Inc.) was deposited. Figure 1 and Figure 2 show molecular structure of $\mathrm{PTB} 7$ (electron donor) and $\mathrm{PC}_{71} \mathrm{BM}$ (electron acceptor), respectively. To prepare precursor solutions for organic polymer layer deposition, PTB7 and $\mathrm{PC}_{71} \mathrm{BM}$ were mixed with solvent mixture of chlorobenzene and chloroform. In addition, other precursor solutions for PTB7 and $\mathrm{PC}_{71} \mathrm{BM}$ were also prepared by adding additional additive solvent of 1,8-Diiodooctane[DIO](Tokyo Chemical Co., Ltd.) to optimize the active layer morphology (Lou et al., 2011).

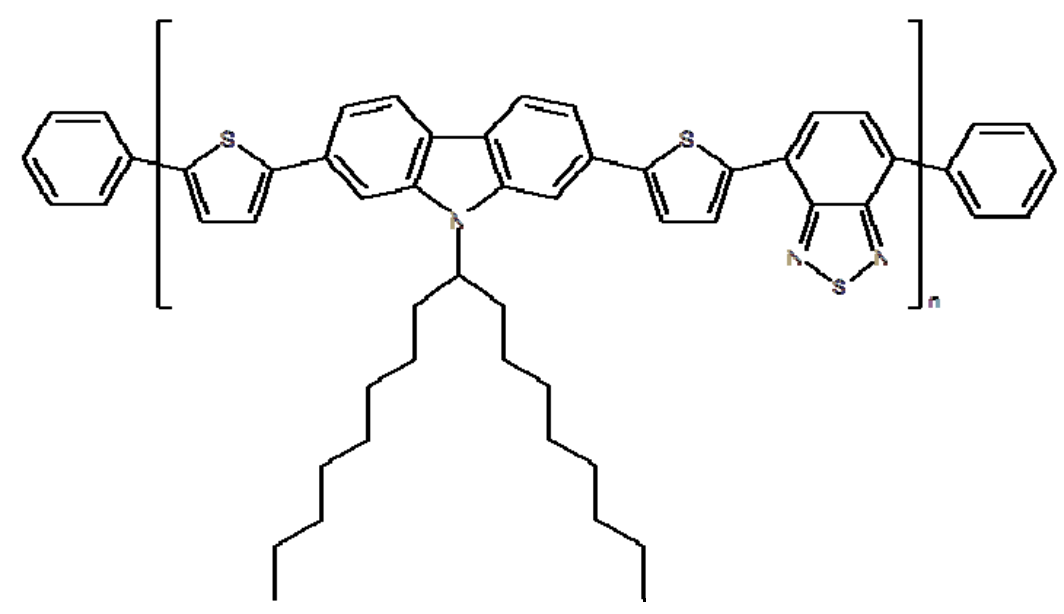

Figure 1. Molecular structure of PTB7

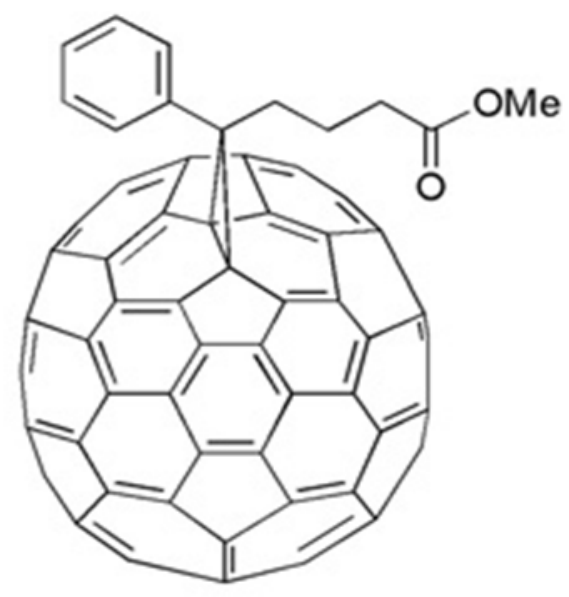

Figure 2. Molecular structure of $\mathrm{PC}_{71} \mathrm{BM}$ 


\subsection{Organic Thin Film Solar Cell Device Fabrication}

ITO coated glass (Asahi Glass; $25 \Omega / \square$ ) was used as substrates. ITO as anode electrode was patterned with $3 \mathrm{~mm}$ line width by using a hard mask and exposing them in hydrogen chloride $(\mathrm{HCl})$ vapor ambient. The patterned ITO substrate was cleaned with distilled water to remove residual hydrogen chloride on the surface. Then the substrates were cleansed ultrasonically prior to organic layer deposition: in acetone, ethanol, and DI water in each 10 min sequence. As hole transporting buffer layer, PEDOT:PSS (Heraeus; Clevios ${ }^{T M}$ P AI4083) thin film of $30 \mathrm{~nm}$ thickness was deposited. Prior to the PEDOT:PSS deposition, the ITO patterned substrates were exposed by UV in vacuum for $10 \mathrm{~min}$ to modify its surface into hydrophilic state for better adhesion. The PEDOT:PSS buffer layer was deposited by spin coating; (1) rotation with $5000 \mathrm{rpm}$ for $30 \mathrm{sec}$; (2) dried in oven at $120^{\circ} \mathrm{C}$. Precursor solution mixtures of $\mathrm{PTB} 7$ and $\mathrm{PC}_{71} \mathrm{BM}$ were prepared with DIO additive and without DIO additive: (1) PTB7 and $\mathrm{PC}_{71} \mathrm{BM}$ were with $1 \mathrm{wt} \%$, respectively; (2) $30 \mathrm{vol} \%$ of DIO was added in PTB7 or $\mathrm{PC}_{71} \mathrm{BM}$ of $1 \mathrm{ml}$. Four different combinations of precursor solutions were used for active layer preparation: (1) PTB7 and $\mathrm{PC}_{71} \mathrm{BM}$; (2) PTB7 with DIO and $\mathrm{PC}_{71} \mathrm{BM}$; (3) PTB7 and $\mathrm{PC}_{71} \mathrm{BM}$ with DIO; (4) PTB7 with DIO and $\mathrm{PC}_{71} \mathrm{BM}$ with DIO. At first, PTB7 precursor solution with or without DIO additive was casted by spin-coating method: rotation with $1000 \mathrm{rpm}$ for $30 \mathrm{sec}$. Then, an interpenetrated hetero-junction structure was obtained by spray-coating method using precursor solution of $\mathrm{PC}_{71} \mathrm{BM}$ with or without DIO additive: nozzle diameter of 0.2 $\mathrm{mm}$; injection pressure of $0.05 \mathrm{MPa}$; spray time of $20 \mathrm{sec} ; N_{2}$ as carrier gas. Finally, cathode electrode of the organic solar cell device was prepared by thermal evaporation of $A l$ in vacuum. Effective light absorption surface area of the resulting organic solar cell device was $9 \mathrm{~mm}^{2}$.

\subsection{Characterization of Organic Active Layers and Organic Solar Cell Devices}

To investigate optical properties comparatively, UV/Vis spectrometer was used for analyses of each single organic layer variety and interpenetrated organic hetero-junction structures. Surface morphology of the organic active layers was investigated by atomic force microscope (AFM). Standard parameters of the fabricated organic thin film solar cell device were obtained from current density (J) - applied voltage (V) characteristics measured in an commercial solar-simulator: light source from Xenon lamp; air mass filter adjusted for AM1.5; light intensity of $100 \mathrm{~mW} / \mathrm{cm}^{2}$. Open circuit voltage $\left(\mathrm{V}_{\mathrm{oc}}\right)$, short circuit current density $\left(\mathrm{J}_{\mathrm{sc}}\right)$, fill factor $(\mathrm{FF})$, and power conversion efficiency (PCE) were obtained, respectively.

\section{Results and Discussion}

UV/Vis spectra of the single organic active layers are given in Figure 3 and Figure 4: Figure 3 for PTB7 with and without DIO additive; Figure 4 for $\mathrm{PC}_{71} \mathrm{BM}$ with and without DIO additive. UV-Vis spectra of the interpenetrated hetero-junction structures are given in Figure 5: (1) $\mathrm{PTB} 7 / \mathrm{PC}_{71} \mathrm{BM}$; (2) (PTB7+DIO)/PC $\mathrm{PC}_{71} \mathrm{BM}$; (3) $\mathrm{PTB} 7 /\left(\mathrm{PC}_{71} \mathrm{BM}+\mathrm{DIO}\right)$; (4) (PTB7+DIO)/(PC 71 BM+DIO).

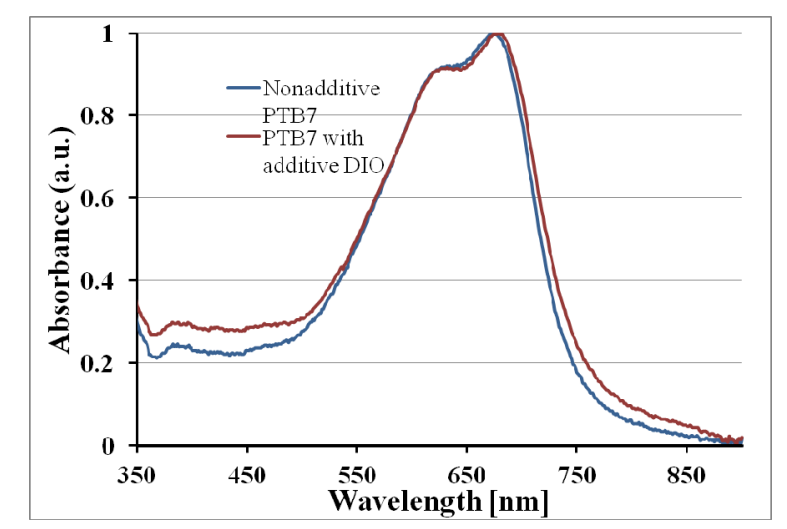

Figure 3. UV/Vis spectra of single layers of PTB7 and PTB7 with and without DIO additive 


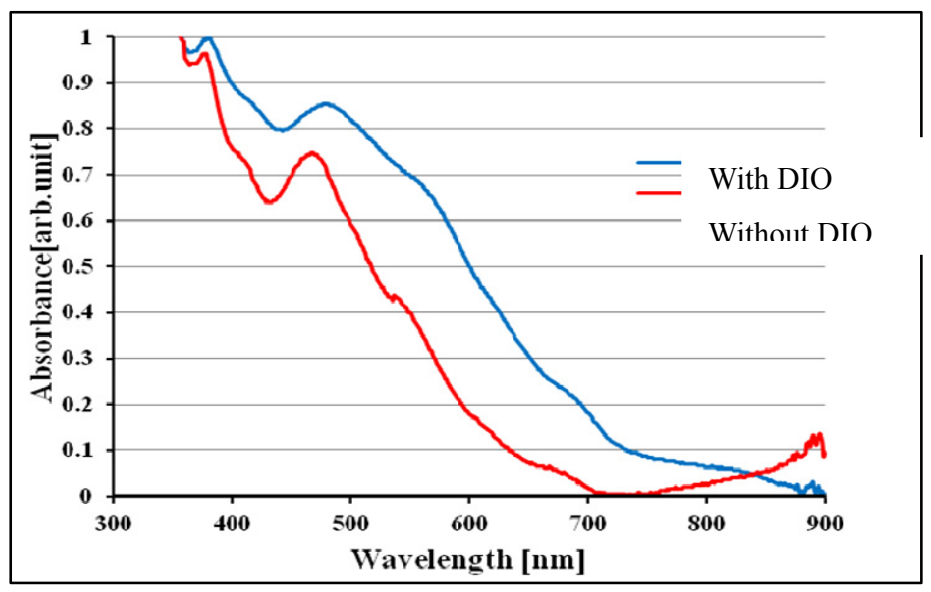

Figure 4. UV/Vis spectra of single layers of $\mathrm{PC}_{71} \mathrm{BM}$ and $\mathrm{PC}_{71} \mathrm{BM}$ with and without DIO additive

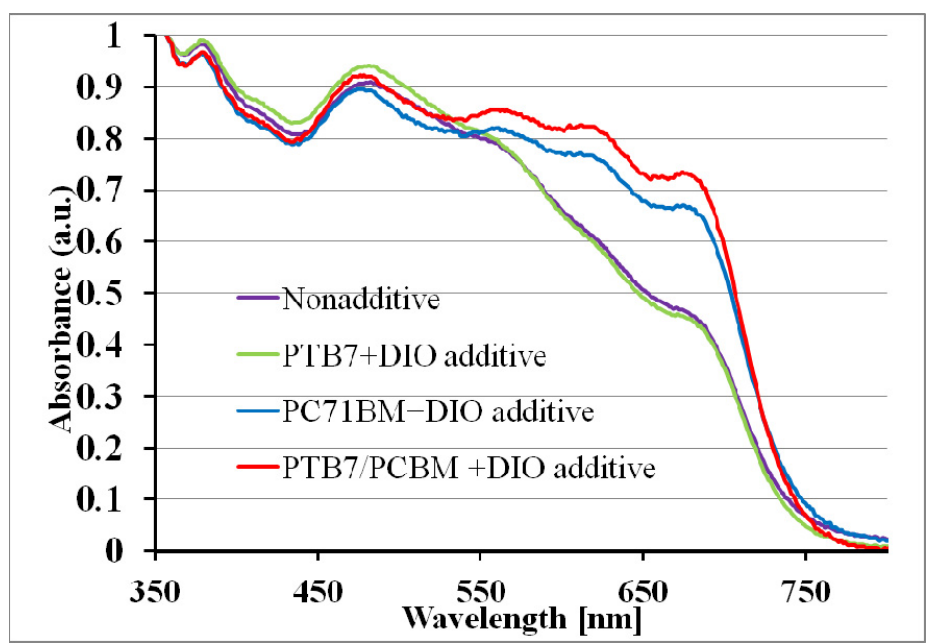

Figure 5. UV/Vis spectra of four interpenetrated hetero-junction structures: $\mathrm{PTB} 7 / \mathrm{PC}_{71} \mathrm{BM}$; (PTB7+DIO)/PC 71 BM; PTB7/(PC 71 BM+DIO); (PTB7+DIO)/(PC 71 BM+DIO)

While the UV/Vis spectrum of the PTB7 with DIO additive (Figure 3) reveal only minute difference from that of PTB7 without additive, UV/Vis spectrum the PC71BM with DIO additive (Figure 4) show a distinct shift to red wavelength range from that of $\mathrm{PC}_{71} \mathrm{BM}$. It can be thought that $\mathrm{DIO}$ additive would cause an inhibiting reaction of agglomerate formation against $\mathrm{PC}_{71} \mathrm{BM}$, which implies that being sprayed $\mathrm{PC}_{71} \mathrm{BM}$ with $\mathrm{DIO}$ additive could be dispersed homogeneously into the PTB7 thin films. Then, an increase of effective area for hetero-interface in the PTB7:PC $\mathrm{PC}_{71} \mathrm{BM}$ composite thin films could be expected. UV/Vis spectra of the hetero-junction structures (Figure 5) show that $\mathrm{PTB} 7 / \mathrm{PC}_{71} \mathrm{BM}$ and $(\mathrm{PTB} 7+\mathrm{DIO}) / \mathrm{PC}_{71} \mathrm{BM}$ structures reveal abrupt decrease of light absorbance from $350 \mathrm{~nm}$ to $700 \mathrm{~nm}$. On the contrary, both hetero-junction structures of $\mathrm{PTB} 7 /\left(\mathrm{PC}_{71} \mathrm{BM}+\mathrm{DIO}\right)$ and $(\mathrm{PTB} 7+\mathrm{DIO}) /\left(\mathrm{PC}_{71} \mathrm{BM}+\mathrm{DIO}\right)$ reveal a broad light absorbance spectra from $350 \mathrm{~nm}$ to $700 \mathrm{~nm}$. Hence, improvement of sun light absorption efficiency could be expected for the hetero-junction structure with $\mathrm{PC}_{71} \mathrm{BM}$ with DIO additive.

Figure 6 shows AFM images for PTB7 single layer without (a) and with (b) DIO additive, respectively. Figure 7 shows AFM images for four different composite layers of (a) PTB7/PC $71 \mathrm{BM}$, (b) $(\mathrm{PTB} 7+\mathrm{DIO}) / \mathrm{PC}_{71} \mathrm{BM}$, (c) $\mathrm{PTB} 7 /\left(\mathrm{PC}_{71} \mathrm{BM}+\mathrm{DIO}\right)$, and $(\mathrm{d})(\mathrm{PTB} 7+\mathrm{DIO}) /\left(\mathrm{PC}_{71} \mathrm{BM}+\mathrm{DIO}\right)$. Surface parameters of the PTB7 layer with and without DIO additive are given in Table 1. Surface parameters of the four different composite layers are given in Table 2. Thickness and surface roughness of the single and composite layers are given in Table 3. 


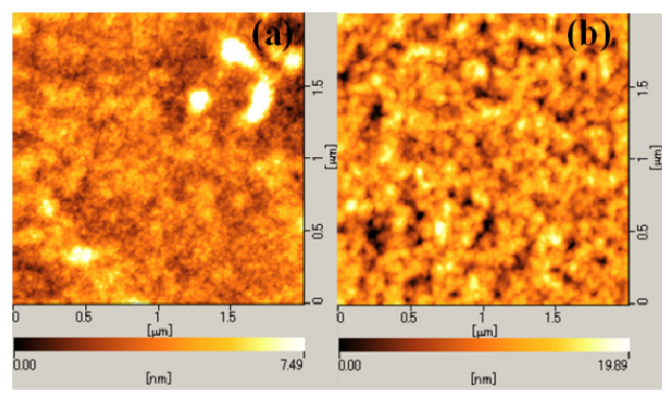

Figure 6. AFM image of PTB7 alone (a) and AFM image of PTB7 with DIO additive (b)

It can be seen from the AFM images (Figure 6) of the PTB7 single layers and surface parameters (Table 1) for PTB7 single layers that the PTB7 with DIO additive reveal higher surface roughness than that of PTB7 without DIO additive. The measured root-mean-square (RMS) roughness is 1.17 and $3.12 \mathrm{~nm}$ for PTB7 without DIO and PTB7 with DIO respectively. It may be caused by accelerated formation of micro grain in PTB7 due to DIO additive (Liang et al., 2010). These micro grains might be the origin of the higher surface roughness for the PTB7 with DIO additive. In addition, the AFM image shown in the Figure 7(b) reveals relatively larger grains on the surface of $\mathrm{PC}_{71} \mathrm{BM}$ without DIO additive interfaced with PTB7 with DIO additive, which implies that larger grains in the underlying PTB7 with DIO additive caused larger grains in the overlaying layer of $\mathrm{PC}_{71} \mathrm{BM}$ without DIO additive. AFM images in the Figure 7(c) and Figure 7(d) show no aggregation on the surface of $\mathrm{PC}_{71} \mathrm{BM}$ with DIO additive interfaced with underlying PTB7 with and without DIO additive. It can be thought that the $\mathrm{DIO}$ additive would serve as good solvent for $\mathrm{PC}_{71} \mathrm{BM}$. Therefore, the surface roughness of the sprayed $\mathrm{PC}_{71} \mathrm{BM}$ could be decreased. The UV/Vis spectrum for the $\mathrm{PC}_{71} \mathrm{BM}$ with DIO additive reveals the same result.

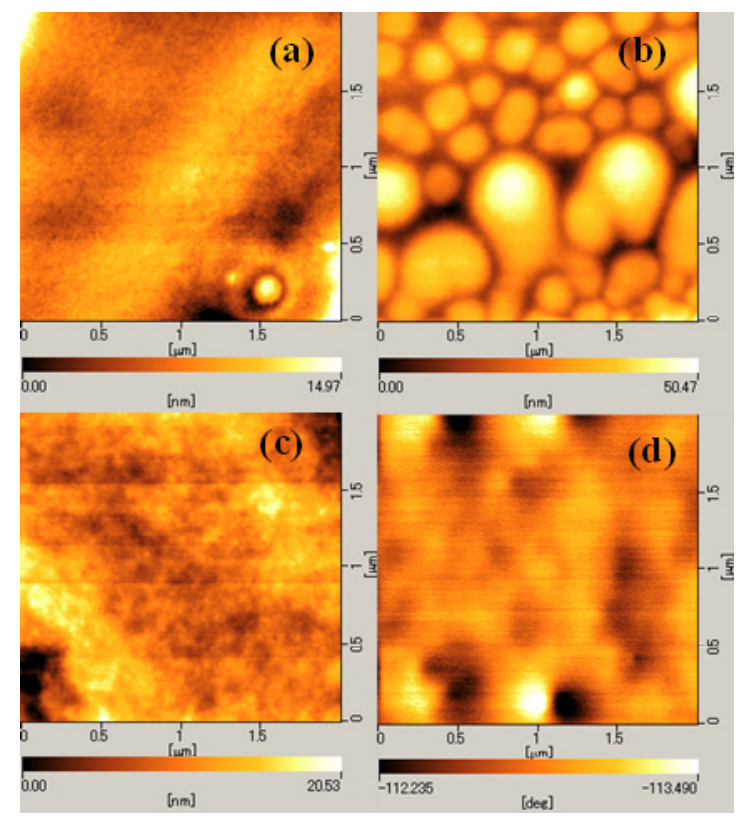

Figure 7. AFM images of four interpenetrated hetero-junction structures:

(a) PTB7/PC ${ }_{71} \mathrm{BM}$; (b) (PTB7+DIO)/PC $\mathrm{P}_{71} \mathrm{BM}$; (c) $\mathrm{PTB} 7 /\left(\mathrm{PC}_{71} \mathrm{BM}+\mathrm{DIO}\right)$;

(d) $(\mathrm{PTB} 7+\mathrm{DIO}) /\left(\mathrm{PC}_{71} \mathrm{BM}+\mathrm{DIO}\right)$ 
Table 1. Surface parameters of PTB7 analyzed by AFM

\begin{tabular}{lcc}
\hline \multicolumn{1}{c}{ Layer } & RMS [nm] & High-Low Diff. [nm] \\
\hline PTB7 without DIO & 1.17 & 11.1 \\
PTB7+ DIO & 3.12 & 24.2 \\
\hline
\end{tabular}

Table 2. Surface parameters of double layers of $\mathrm{PTB} 7 / \mathrm{PC}_{71} \mathrm{BM}$ analyzed by AFM

\begin{tabular}{lll}
\hline Layer & RMS [nm] & High-Low Diff. [nm] \\
\hline PTB7/PC ${ }_{71} \mathrm{BM}$ & 2.16 & 22.6 \\
$(\mathrm{PTB} 7+\mathrm{DIO}) / \mathrm{PC}_{71} \mathrm{BM}$ & 13.0 & 57.7 \\
$\mathrm{PTB} 7 /\left(\mathrm{PC}_{71} \mathrm{BM}+\mathrm{DIO}\right)$ & 3.19 & 23.7 \\
$(\mathrm{PTB} 7+\mathrm{DIO}) /\left(\mathrm{PC}_{71} \mathrm{BM}+\mathrm{DIO}\right)$ & 3.23 & 26.5 \\
\hline
\end{tabular}

Table 3. Thickness and surface roughness of single and double layers

\begin{tabular}{|c|c|c|}
\hline Layer & Thickness [nm] & RMS [nm] \\
\hline PTB7 without DIO & 70 & 1.17 \\
\hline PTB7+DIO & 80 & 3.12 \\
\hline $\mathrm{PTB} 7 / \mathrm{PC}_{71} \mathrm{BM}$ & 150 & 2.16 \\
\hline$(\mathrm{PTB} 7+\mathrm{DIO}) / \mathrm{PC}_{71} \mathrm{BM}$ & 160 & 13.0 \\
\hline $\mathrm{PTB} 7 /\left(\mathrm{PC}_{71} \mathrm{BM}+\mathrm{DIO}\right)$ & 160 & 3.19 \\
\hline$(\mathrm{PTB} 7+\mathrm{DIO}) /\left(\mathrm{PC}_{71} \mathrm{BM}+\mathrm{DIO}\right)$ & 170 & 3.23 \\
\hline
\end{tabular}

Figure 8 shows $\mathrm{J}-\mathrm{V}$ characteristics of the organic solar cell devices with the interpenetrated hetero-junction structure. Essential performance parameters obtained from the J-Vcharacteristics are summarized in Table 4. It can be seen that addition of DIO additive in PTB7 could not be resulted in improvement of performance for the resulting organic solar cell device. On the contrary, the organic solar cells with $\mathrm{PC}_{71} \mathrm{BM}$ with $\mathrm{DIO}$ additive reveal drastic improvement of performance. Especially, distinctive increase of short circuit current density $\left(\mathrm{J}_{\mathrm{sc}}\right)$ could be obtained for the organic solar cells with $\mathrm{PC}_{71} \mathrm{BM}$ with $\mathrm{DIO}$ additive. It can be thought that the DIO additive influenced on an increase of interpenetrated interface surface between $\mathrm{PC}_{71} \mathrm{BM}$ and PTB7 and hence, increased exciton generation rates. Following two factors could be thought for the positive effect by the DIO additive: (1) increased penetrating time of the $\mathrm{PC}_{71} \mathrm{BM}$ into the underlying PTB7 due to retarded drying time because of high boiling temperature of $144^{\circ} \mathrm{C}$ (at $2 \mathrm{mmHg}$ ) of the DIO additive; (2) Suppressed formation of larger grain in the $\mathrm{PC}_{71} \mathrm{BM}$.

Table 4. Characteristic parameters of organic thin film solar cell with different hetero-junction structures of $\mathrm{PTB} 7 / \mathrm{PC}_{71} \mathrm{BM}$

\begin{tabular}{|c|c|c|c|c|}
\hline Hetero-Junction & $\mathrm{V}_{\mathrm{oc}}[\mathrm{V}]$ & $\mathrm{J}_{\mathrm{sc}}\left[\mathrm{mA} / \mathrm{cm}^{2}\right]$ & Fill Factor & $\operatorname{PCE}(\eta)[\%]$ \\
\hline $\mathrm{PTB} 7 / \mathrm{PC}_{71} \mathrm{BM}$ & 0.75 & 3.24 & 0.49 & 1.24 \\
\hline$(\mathrm{PTB} 7+\mathrm{DIO}) / \mathrm{PC}_{71} \mathrm{BM}$ & 0.76 & 3.43 & 0.48 & 1.24 \\
\hline $\mathrm{PTB} 7 /\left(\mathrm{PC}_{71} \mathrm{BM}+\mathrm{DIO}\right)$ & 0.74 & 10.51 & 0.45 & 3.54 \\
\hline$(\mathrm{PTB} 7+\mathrm{DIO}) /\left(\mathrm{PC}_{71} \mathrm{BM}+\mathrm{DIO}\right)$ & 0.74 & 9.84 & 0.46 & 3.46 \\
\hline
\end{tabular}




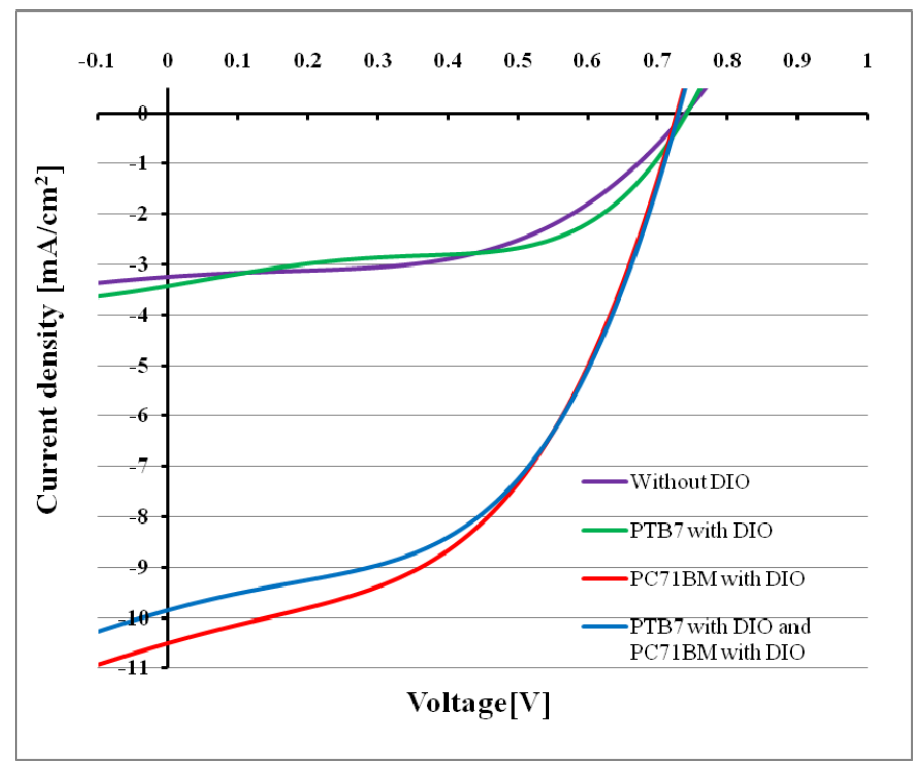

Figure 8. J-V characteristic of organic thin film solar cell with four interpenetrated hetero-junction structurs: PTB7/PC 71 BM; (PTB7+DIO)/PC ${ }_{71} \mathrm{BM}$; PTB7/(PC 71 BM+DIO); (PTB7+DIO)/(PC 71 BM+DIO)

\section{Summary and Conclusion}

In this report, organic thin film solar cell devices were fabricated with an interpenetrated hetero-junction structure of $\mathrm{PTB} 7 / \mathrm{PC}_{71} \mathrm{BM}$. Light absorbance and surface morphology of the single layers and composite layers were analyzed comparatively. Performance of the resulting organic solar cell devices were investigated in relation with four different combinations of electron donor and electron accepter layers. A wet process for the interpenetrated hetero-junction structure was successfully carried out for fabrication of organic solar cell device: (1) spin-coating method for electron donor layer of PTB7; (2) spray-coating method for electron acceptor layer of $\mathrm{PC}_{71} \mathrm{BM}$. The DIO additive in the $\mathrm{PC}_{71} \mathrm{BM}$ resulted in drastic improvement of $\mathrm{PCE}(\eta=3.54 \%)$ from that $(\eta=1.24 \%)$ of without DIO additive, which was influenced by increased short circuit current density $\left(\mathrm{J}_{\mathrm{sc}}\right)$.

\section{Acknowledgments}

This research was partly supported by "Chubu science and technology center [Overseas researcher invitation support ofNAGOYA environmental field]", "MEXT Private University Project Grant under contract \# S1001033", "JST Adaptableand Seamless Technology transfer Program through target-driven R\&D \#AS232Z02610B" and "Joint research betweenAIT and NIPPON DENWA SHISETSU".

\section{References}

Deibel, C., \& Dyakonov, V. (2010). Polymer-fullerene bulk heterojunction solar cells. Rep. Prog. Phys., 73, 096401. http://dx.doi.org/10.1088/0034-4885/73/9/096401

Deibel, C., Dyakonov, V., \& Brabec, C. J. (2010). Organic Bulk-Heterojunction Solar Cells. IEEE Journal of Selected Topics in Quantum Electronics, 16, 1517-1527. http://dx.doi.org/ 10.1109/JSTQE.2010.2048892

Dennler, G., Scharber, M. C., \& Brabec, C. J. (2009). Polymer-Fullerene Bulk-Heterojunction Solar Cells. Adv. Mater., 21, 1323-1338. http://dx.doi.org/10.1002/adma.200801283

Liang, Y., Xu, Z., Xia, J., Tsai, S., Wu, Y., Li, G., ... Yu, L. (2010). For the bright Future - Bulk Heterojunction Polymer Solar Cells with Power conversion Efficiency of 7.4\%. Adv. Mater, 22, E135. http://dx.doi.org/ 10.1002/adma.200903528

Lou, S. J., Szarko, J. M., Xu, T., Yu, L., Marks, T. J., \& Chen, L. X. (2011). Effect of Additives on the Morphology of solution phase Aggregates formed by active layer components of high-efficiency organic solar cell. J. Am. Chem. Soc., 133, 20661-20663. http://dx.doi.org/ 10.1021/ja2085564

Nam, Y. M., Huh, J., \& Jo, W. H. (2010). Optimization of thickness and morphology of active layer for high performance of bulk-heterojunction organic solar cells. Solar Energy Materials and Solar Cells, 94, 1118-1124. http://dx.doi.org/10.1016/j.solmat.2010.02.041

Ohkita, H., \& Ito, S. (2011). Transient absorption spectroscopy of polymer-based thin-film solar cells. Polymer, 
52, 4397-4417. http://dx.doi.org/10.1016/j.polymer.2011.06.061

Park, S. E., Hwang, J. Y., Kim, K., Jung, B., \& Hwang, W. J. (2011). Spray deposition of electrohydrodynamically atomized polymer mixture for active layer fabrication in organic photovoltaics. Solar Energy Materials \& Solar Cells, 95, 352. http://dx.doi.org/10.1016/j.solmat.2010.04.057

Park, S. H., Roy, A., Beaupre, S., Cho, S., Coates, N., Moon, J. S., ... Heeger, A. J. (2009). Bulk heterojunction solar cells with internal quantum efficiency approaching 100\%. Nature Photonics, 3, 297. http://dx.doi.org/10.1038/nphoton.2009.69

Yang, J., Chen, W., Yu, B., Wang, H., \& Yan, D. (2012). Organic tandem solar cell using active inter-connecting layer. Organic Electronics, 13, 1018-1022. http://dx.doi.org/10.1016/j.orgel.2012.02.015 